\title{
Sublingual Allergen-Specific Immunotherapy Adjuvanted with Monophosphoryl Lipid A: A Phase I/Ila Study
}

\author{
Oliver Pfaar ${ }^{a, b} \quad$ Christine Barth ${ }^{a, b} \quad$ Christine Jaschke ${ }^{a, b} \quad$ Karl Hörmann ${ }^{b}$ \\ Ludger Klimek ${ }^{a, b}$ \\ ${ }^{a}$ Center for Rhinology and Allergology, Wiesbaden, and bepartment of Otorhinolaryngology, \\ Head and Neck Surgery, University Hospital Mannheim, Mannheim, Germany
}

\section{Key Words}

Adjuvant $\cdot$ Allergic rhinitis $\cdot$ Grass pollen $\cdot$ Monophosphoryl lipid $A \cdot$ Sublingual immunotherapy

\begin{abstract}
Background: Sublingual immunotherapy (SLIT) allergy vaccines have an excellent safety profile, but opinions vary on their efficacy, and treatment regimens are often lengthy. This study assessed the effects of the Toll-like receptor 4 agonist monophosphoryl lipid A (MPL $\left.{ }^{\circledR}\right)$ on safety/tolerability and clinical and immunological efficacy when combined with grass pollen SLIT formulations in treating patients with seasonal allergic rhinitis. This is the first reported study of adjuvanted SLIT. Methods: In this double-blind placebocontrolled phase I/lla study, 80 grass pollen-sensitive subjects were randomized into 4 groups of 20 subjects to receive daily treatment for 8 weeks. Sixteen patients per group received SLIT and 4 received placebo. The formulation given to each group varied with respect to grass pollen extract and MPL content. Grass allergen nasal challenge tests (NCTs) were performed prior to dosing and in weeks 4 and 10. Grass pollen-specific immunoglobulin $\mathrm{G}(\mathrm{lgG})$ and $\mathrm{lgE}$ antibodies were measured at baseline and prior to dosing in weeks 2,3 , 4, 5 and 10. Results: Local and systemic adverse events were generally comparable for patients who received active treatment and placebo. Patients in the 2 groups given SLIT containing the highest amount of MPL experienced the highest
\end{abstract}

proportion of negative NCTs after 10 weeks ( 47 and $44 \%$, vs. $20 \%$ with placebo). These patients also showed earlier median increases in specific lg $\mathrm{G}$ and smaller increases in IgE levels than those receiving other formulations. Conclusions: These results suggest that SLIT preparations containing MPL are well tolerated and alter the immunological response to grass antigens after 3 weeks of exposure, with an associated suppression of nasal challenge responses.

Copyright $\odot 2010$ S. Karger AG, Basel

\section{Introduction}

Specific immunotherapy (SIT) is recognized as the only curative treatment for immunoglobulin $\mathrm{E}$ (IgE)-mediated allergies. Long-lasting efficacy which persists after treatment, the prevention of new sensitizations and a reduction in the risk of developing asthma in children with allergic rhinitis have been demonstrated in several studies [1-4].

Although SIT is highly effective, the subcutaneous route of administration (subcutaneous immunotherapy,

The results of this study were presented in part as oral presentation at the XXVIth Congress of the European Academy of Allergy and Clinical Immunology (EAACI) in Göteborg, Sweden, June 2007.

\section{KARGER}

Fax +41613061234 E-Mail karger@karger.ch www.karger.com
Correspondence to: Priv.-Doz. Dr. Oliver Pfaar

Department of Otorhinolaryngology, University Hospital Mannheim

Center for Rhinology and Allergology

An den Quellen 10, DE-65183 Wiesbaden (Germany)

Tel. +49 611890 4381, Fax +49611890 4382, E-Mail oliver.pfaar@allergiezentrum.org 
SCIT) is unacceptable or inconvenient for some patients. Also, conventional SCIT has previously been associated with life-threatening adverse reactions [5], and alternative regimens and routes of administration have been investigated.

Sublingual immunotherapy (SLIT) is advantageous in that it can be self-administered at home, requiring fewer clinic visits. The efficacy of SLIT is now well documented, with several phase III studies showing success with both adults and children as young as 5 years of age [6-9]. All studies have shown high tolerance with typically minor local side effects. No fatalities have been associated with SLIT. However, as with conventional SCIT, SLIT has a lengthy administration course. Efficacy for alleviation of seasonal allergic rhinitis caused by grass pollen has been demonstrated, but typically the dosing is once daily for 16 weeks prior to the pollen season and then throughout the season [7,9], thus requiring a considerable commitment from the patient.

An imbalance of Thelper (Th)2/Th1 differentiation in the immune system has been recognized as a major reason for the induction and maintenance of IgE-mediated sensitization [10]. The beneficial effect of SIT may be caused by a shift in the allergen-specific Th cells from a Th2 skew to a more Th1-like profile [11-13]. Also, recent scientific interest has been focused on eliciting regulatory $\mathrm{T}$ cells (Treg) capable of downregulating both Th1 and Th2 responses through the production of interleukin (IL)-10 and/or transforming growth factor (TGF)- $\beta$ [1417]. Furthermore, preliminary clinical studies on SLIT indicated a similar early Treg-related interleukin production with consequent downmodulation of the immune response [18-20]. Although there have been several important studies published, most have been associated with particularly long periods of treatment. Following clinically successful 3-year SLIT for house dust mite hypersensitivity, cultures of patients' peripheral blood mononuclear cells (PBMCs) showed both a decreased T cell population and increased IL-10 production [21]. In a 2-year study of house dust mite SLIT, PBMC analysis showed that IL-5 production was significantly reduced after 6 months, concurrently with production of TGF- $\beta$; IL-10 secretion and Der p 2-specific IgG4 were maximal after 24 months of treatment [22].

A pediatric study employing tree pollen SLIT with treatment for up to 18 months examined cytokine mRNA expression in PBMCs and found a rise in IL-10 and a reduction in IL-5 [23]. Whilst these studies have been important for establishing the immunological effects of SLIT (and the similarities to SCIT), there has been little comparison of early with later profiles. However, a birch pollen SLIT study was particularly informative, also providing cytokine data from PBMCs following 4 and 52 weeks of immunotherapy. After 4 weeks, FoxP3 and IL-10 had increased, while IL- 4 and IFN- $\gamma$ had decreased. After 52 weeks, IFN- $\gamma$ had increased, while IL-10, FoxP3 and IL-4 had decreased. Thus there was an early Treg suppression via IL-10, but later the immune deviation corresponded more to Th0/Th1-like activity [24]. From these data, a clinical response could be predicted, not via a constant mechanism but as a result of a suppressive mechanism phasing out Th2 effects and then turning to a more Th1-like skew. Simplistically, an adjuvant could of course hopefully 'hasten' the progression, but the clinical and immunological outcomes would be dependent on the nature of the adjuvant, the dosage and the length of treatment.

The immunological adjuvant monophosphoryl lipid A (MPL ${ }^{\circledR}$; GlaxoSmithKline Biologicals, Rixensart, Belgium) has been incorporated in SCIT in order to enhance clinical and immunological efficacy [25-27]. MPL is a detoxified, attenuated form of the lipid A component of the lipopolysaccharide of Salmonella minnesota and is a Tolllike receptor 4 agonist $[27,28]$. The inclusion of MPL reduces the number of injections required for effective SCIT and may thereby improve compliance with the regimen and provide pharmacoeconomic benefits [27].

In vitro studies on PBMCs from patients with seasonal allergic rhinitis to grass pollen showed that MPL added to grass pollen extract resulted in the suppression of allergen-induced peripheral Th2 cell responses in favor of protective Th1 responses in an IL-12- and monocyte-dependent fashion [29]. An allergoid preparation including MPL was found to be clinically and immunologically effective in a multicenter, placebo-controlled, randomized, double-blind clinical study on 141 grass pollen-sensitive subjects [25]. Four preseasonal injections of a vaccine containing tyrosine-adsorbed, glutaraldehyde-modified grass pollen extract plus MPL (Pollinex ${ }^{\circledR}$ Quattro) significantly improved patients' symptoms and combined medication/symptom scores in the grass pollen season following treatment. It was hypothesized that the $\mathrm{T}$ cell switch was enhanced by the adjuvant MPL, which possibly enables a shorter therapy course to be effective [2527].

Recently, in vitro evidence has suggested that MPL is likely to promote tolerogenic properties in oral mucosal Langerhans cells [30]. It is therefore possible that MPL might enhance the immunologic properties of SLIT formulations, enabling a shorter treatment course to be clin- 
ically effective (as with SCIT), although this hypothesis has not yet been clinically investigated.

We aimed to evaluate the safety and tolerability of MPL-adjuvanted grass pollen allergen SLIT and additionally investigate the effect of the addition of MPL on the early immunologic and clinical characteristics of a shortterm grass pollen extract SLIT formulation outside of the grass pollen season. The preliminary data from this phase I/IIa trial would encourage further design of larger studies.

\section{Methods}

This was a single-center, double-blind, randomized, dose escalation, placebo-controlled phase I/IIa study performed in Germany with approval from the independent ethics committee of the State Medical Association of Baden-Württemberg and the Paul Ehrlich Institute. All subjects gave written informed consent to participate in the study.

\section{Subjects and Study Protocol}

Male and female subjects aged 18-65 years who were sensitive to grass pollen and reported seasonal allergy symptoms were included in the study. Further inclusion criteria were: no grass pollen SIT within the past 3 years; a positive skin prick test wheal of $>4 \mathrm{~mm}$ in diameter from a mixture of pollens from 12 temperatezone grasses [B2 grass mixture prick test solution, Allergy Therapeutics (UK) Ltd.], a positive RAST or equivalent ( $\geq$ class 2 ) test to grasses and a positive test result on the nasal challenge test (NCT) with grass pollen allergen. The $\mathrm{B} 2$ grass mixture consists of 12 grasses: oat grass, crested dogtail, cocksfoot, rye grass, meadow grass, vernal, bent, brome, meadow foxtail, timothy grass, meadow fescue and Yorkshire fog. These allergenically cross-reacting grasses come from the subfamily Pooideae, family Poaceae (Gramineae).

Exclusion criteria included sensitization to tree pollen (birch, alder and hazel) or perennial allergens which might have interfered with the clinical trial protocol (confirmed by positive case history and skin prick test) and/or allergy symptoms during screening. The perennial allergens in question were house dust mites (Dermatophagoides pteronyssinus, Dermatophagoides farinae), molds (Cladosporium cladosporiodes, Alternaria alternata, Penicillium chrysogenum, Aspergillus fumigatus) and epithelia (cat, Felis domesticus; dog, Canis familiaris; horse, Equus caballus).

Patients were excluded if they had contraindications for SIT, had received any vaccinations within the preceding 3 months or MPL-containing products within the last 12 months or suffered from atopic dermatitis or other skin diseases which could influence the skin test results.

After completing screening, 80 subjects were randomized into 4 groups, with 16 subjects per group receiving active SLIT and 4 receiving placebo. The SLIT formulations contained a buffered aqueous glycerol extract of 12 mixed grass pollens (Allergy Therapeutics, B2 grass mixture, standardized and quantified by timothy grass major allergen Phleum pratense $\mathrm{Phl} p \mathrm{p}$ ) and MPL as follows:

Group 1 (GP9.5): $9.45 \mu \mathrm{g}$ of Phl p 1; group 2 (GP9.5 + MPL21): $9.45 \mu \mathrm{g}$ of Phl p $1+21 \mu \mathrm{g}$ of MPL; group 3 (GP9.5 + MPL52): 9.45 $\mu \mathrm{g}$ of Phl p $1+52.5 \mu \mathrm{g}$ of MPL, and group 4 (GP19 + MPL52): $19.04 \mu \mathrm{g}$ of Phl p $1+52.5 \mu \mathrm{g}$ of MPL.

Group GP19 was a dose escalation group which was guided by tolerability and limited to $19.04 \mu \mathrm{g}$ of $\mathrm{Phl} \mathrm{p} 1$ /dose for all subjects after 2 subjects ( 1 who received active therapy and 1 who received placebo) experienced moderate local reactions on receiving the next dosage step of $38.07 \mu \mathrm{g}$ of Phl p 1/dose. The planned final dose was $57.12 \mu \mathrm{g}$ of Phl p 1.

Placebo solutions contained buffered glycerine solution and flavoring to match the active SLIT. All formulations were manufactured by Allergy Therapeutics (UK) Ltd., Worthing, UK.

One subject (GP9.5) withdrew consent after the first dose and was replaced, but was included in the safety population $(n=81)$.

The first dose of trial medication was administered on day 1 in the trial unit. Except for dosing during visits to the trial unit in weeks 2, 3, 4, 5 and 8 and day 2 dosing of group GP19 + MPL52, all other doses were administered daily by the subjects at home. The final dose of study medication was administered in the trial unit at visit 6 (week $8 \pm 3$ days). Each dose of trial medication was administered as 3 pumps of a sublingual solution $(0.21 \mathrm{ml}$ in total) from a dosing pump, starting from day 1 , with the solution kept under the tongue for about 1-2 min and then swallowed. Subjects were instructed to terminate administration of the trial medication immediately if they experienced any illness.

Treatment periods were as follows: 15 December 2005-20 March 2006 (group GP9.5), 26 January 2006-1 April 2006 (group GP9.5 + MPL21), 4 February 2006-18 April 2006 (group GP9.5 + MPL52) and 9 October 2006-21 December 2006 (group GP19 + MPL52). Therefore, treatment of the first 3 groups overlapped with the tree pollen season, but tree pollen allergy was an exclusion criterion.

\section{Nasal Challenge Tests}

NCTs were completed as an inclusion criterion on day 1 prior to dosing and again in weeks 4 and 10 ( 2 weeks after completion of the 8-week therapy course). A positive NCT was required at inclusion in order to ensure that subjects were sensitive to the test allergen in the applied dose. The NCT was performed in accordance with previously validated protocols $[31,32]$ modified to the position paper of the German Society for Allergology and Clinical Immunology [33] as described below.

Rhinoscopy was performed prior to the measurement of nasal airflow (by rhinomanometry). Firstly, airflow was measured at $150 \mathrm{~Pa}$ in both nostrils to obtain a baseline value. Then, a saline solution $(0.9 \% \mathrm{w} / \mathrm{v})$ was sprayed into the nose and the airflow was measured again after $10 \mathrm{~min}$; if airflow had decreased by more than $40 \%$ after the application of saline, the NCT was cancelled for that visit (or discontinued if this occurred prior to dosing on day 1), as reduced airflow in response to saline may have complicated the interpretation of the results. Then a grass allergen solution $(0.1 \mathrm{ml}$, containing $2 \mu \mathrm{g}$ of allergen extract) was sprayed into the nostril in which the highest baseline airflow had been recorded, and the airflow was remeasured and recorded after $10 \mathrm{~min}$. In addition, subjects recorded symptom scores for secretion, irritation/sneezing and systemic symptoms on a scale of $0-2(0=$ none/ little; 1 = moderate; 2 = severe). Examples of systemic symptoms were tears, itchy palate or ears (score of 1), conjunctivitis, urticaria and shortness of breath (score of 2).

A positive test result was concluded if the sum of the scores for secretion, irritation and systemic reactions was more than 3 , or if 
Table 1. Patient baseline characteristics and pollen sensitivities (safety population)

\begin{tabular}{|c|c|c|c|c|c|}
\hline Parameter & $\begin{array}{l}\text { GP } 9.5 \\
\text { (active) }\end{array}$ & $\begin{array}{l}\text { GP9.5 + MPL21 } \\
\text { (active) }\end{array}$ & $\begin{array}{l}\text { GP9.5 + MPL52 } \\
\text { (active) }\end{array}$ & $\begin{array}{l}\text { GP19 + MPL52 } \\
\text { (active) }\end{array}$ & All placebo \\
\hline Number of subjects & $17^{1}$ & 16 & 16 & 16 & 16 \\
\hline Males/females, $\mathrm{n}$ & $9 / 8$ & $10 / 6$ & $10 / 6$ & $9 / 7$ & $10 / 6$ \\
\hline Mean age, years (SD) & $37.6(13.5)$ & $36.4(11.30)$ & $37.4(11.19)$ & $31.4(12.58)$ & $36.8(12.22)$ \\
\hline Range & $18-60$ & $21-63$ & $19-59$ & $18-64$ & $19-63$ \\
\hline Current smokers ( $\leq 10$ cigarettes/day), $\mathrm{n}$ & 6 & 2 & 1 & 3 & 5 \\
\hline Mean grass-specific IgE, kU/l (SD) & $28.92(32.67)$ & $27.74(26.63)$ & $16.94(12.82)$ & $27.21(28.67)$ & $16.23(11.40)$ \\
\hline \multicolumn{6}{|l|}{ Mean wheal size on skin prick tests, $\mathrm{mm}$} \\
\hline $\mathrm{B} 2$ grass pollen mix $(\mathrm{SD})$ & $29.7(9.43)$ & $27.1(10.75)$ & $23.6(9.63)$ & $25.8(11.71)$ & $28.1(9.82)$ \\
\hline Range & $13-50$ & $10-50$ & $7-42$ & $7-45$ & $10-40$ \\
\hline Histamine $0.1 \%(\mathrm{SD})$ & $12.9(6.95)$ & $11.9(4.01)$ & $7.9(3.56)$ & $12.8(6.20)$ & $15.9(21.05)$ \\
\hline Range & $5-32$ & $8-20$ & $0-13$ & $2-25$ & $5-92$ \\
\hline
\end{tabular}

\footnotetext{
${ }^{1}$ One patient dropped out of the study after receiving the first dose of study medication and was replaced, but was still included in the safety population.
}

the reduction of airflow was $>40 \%$. To confirm a negative test result (symptom score of 3 or less, or reduction of airflow $<40 \%$ ), further airflow measurements were performed 20 and 30 min after application of the allergen solution.

\section{Antibody Assays}

Analysis of timothy grass-specific IgG was performed at a central laboratory (Dr. Robert G. Hamilton, Johns Hopkins University Dermatology, Allergy and Clinical Immunology Reference Laboratory, Baltimore, Md., USA) using a solid-phase radioimmunoassay with ${ }^{125} \mathrm{I}$-labeled streptococcal protein $\mathrm{G}$ (Calbiochem). The lower limit of quantification of the assay was $400 \mathrm{ng} /$ $\mathrm{ml}$ equivalent (concentrations below this limit were considered to be $400 \mathrm{ng} / \mathrm{ml}$ equivalent). Grass-specific IgE (Dactylus glomerata, Festuca elatior, Lolium perenne, Phleum pratense, Poa pratensis) analysis was performed at a central laboratory (Dr. Michael Klein, Kaiserslautern, Germany) using a chemiluminescence immunoassay (ImmunoCAP, Phadia).

\section{Safety and Tolerability}

Clinical chemistry parameters (blood, urine analysis) and ECGs were measured at screening and at the end of the study. Vital signs (pulse and blood pressure) were monitored prior to dosing, after dosing on day 1, after weeks $2,3,4,5$ and 8 and at the final visit.

All adverse events (AEs) were recorded during the study, and causality was assessed by the investigator. AEs with a causal relationship to treatment were categorized on each administration day, including duration.

\section{Statistics}

All measured variables were tabulated using descriptive statistics, including the number of observations and absolute and relative frequency of categorical variables. For the continuous variables, the number of observations, arithmetic mean, standard deviation (SD), coefficient of variation (if appropriate), median, minimum and maximum were calculated. The influence of different doses of MPL on continuous immune response and efficacy variables was assessed by an analysis of variance method. For the NCTs, a Cochran-Armitage trend analysis was applied, and significance was calculated by the within-group difference from baseline to week 10 .

\section{Results}

\section{Patients}

The groups were well balanced in terms of demographic variables and sensitivity to grass pollen at the start of the study (table 1).

\section{Safety and Tolerability}

No clinically significant values out of normal ranges were observed, neither for measurement of vital signs nor for ECG recordings. Minor clinical chemistry abnormalities were found in 1 subject whose creatinine kinase level oscillated under and over the higher reference value and in another subject who had bacteria in the urine at one visit due to cystitis. Findings for the actively treated groups were comparable to those from the placebo groups.

No serious AEs occurred during this study. The majority of treatment-related AEs were local, and their incidence did not appear to vary over time. The most common local AEs were pruritus, swelling and a burning sensation in the oral cavity (table 2). There were no withdrawals due to AEs, and all events resolved without complications. AEs were observed in 64 of the 81 sub- 
jects. The intensity of the total of 163 AEs was predominantly mild (141 events), and 21 were moderate. One event was severe (subcutaneous abscess, not related to treatment). Treatment-related systemic AEs were relatively rare and included dizziness, fatigue, nausea, pruritus, rhinitis, nasal dryness, nasal congestion and sneezing. All treatment-related systemic AEs were of mild intensity. The percentages of subjects with treatment-related systemic AEs were as follows: placebo, 12.5\%; GP9.5, 11.8\%; GP9.5 + MPL21, 37.5\%; GP9.5 + MPL52, 37.5\%; GP19 + MPL52, 6.3\%. The incidence of systemic reactions in patients on active therapy was not significantly different compared to those on placebo treatment.

The number of days on which mild or moderate local AEs were recorded appeared to decrease with increasing MPL dose, i.e. 321, 289 and 228 total days for the first 3 groups, respectively; these groups received the same amount of allergen per dose.

\section{Nasal Challenge Tests}

All subjects demonstrated a positive NCT at baseline. The proportions of negative NCT results in weeks 4 and 10 are shown in figure 1 . In week 4 , the allergen-only group showed the highest level of NCTs. However, the adjuvanted groups were greatly improved in week 10 , when the proportion of negative NCTs in groups GP9.5 + MPL52 and GP19 + MPL52 were 47 and 44\%, respectively, compared with $0 \%$ at baseline. A trend analysis from baseline to week 10 within individual treatment groups showed a significant increase in negative NCTs for active SLIT for groups GP9.5 + MPL52 (p = 0.002) and GP19+ MPL52 ( $\mathrm{p}=0.002)$.

\section{Antibody Assays}

IgG Levels

Median IgG levels remained unchanged over the assessment period in the placebo group (fig. 2a). In contrast, there was an early increase (week 3 ) in grass pollen-specific IgG in the patients who received the highest dose of MPL (groups GP9.5 + MPL52 and GP19 + MPL52). Increases in IgG were not seen in other groups until weeks 5 and 10 (groups GP9.5 + MPL21 and GP9.5, respectively). In week 10 , IgG levels were significantly raised compared with placebo in groups GP9.5 + MPL21 and GP19 + MPL52; both $\mathrm{p}<0.05$ ), with the corresponding IgG increase in group GP9.5 + MPL52 just missing statistical significance $(\mathrm{p}=0.0586)$. However, the small size of the treatment groups makes statistical comparisons difficult to interpret. There was considerable heterogeneity in the

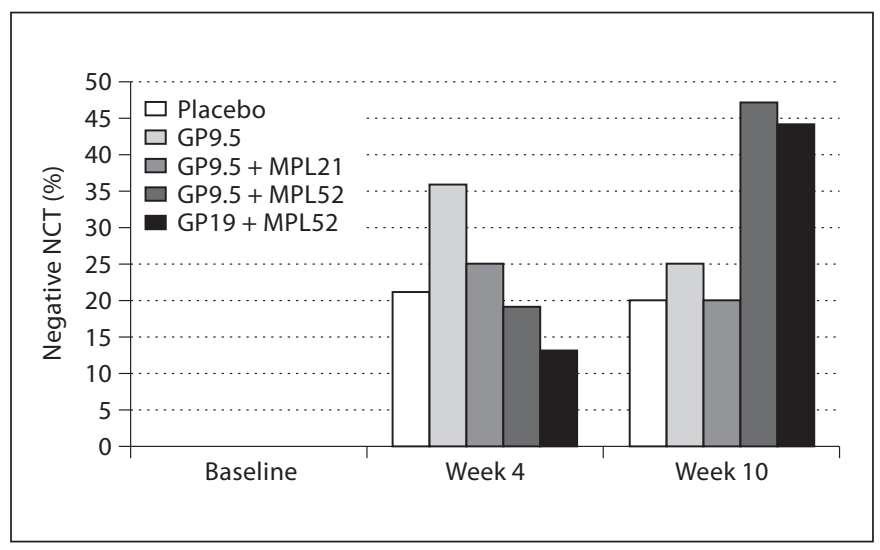

Fig. 1. Negative NCTs during the study.

Table 2. Most frequent local AEs during the study

\begin{tabular}{lccccc}
\hline & $\begin{array}{l}\text { GP9.5 } \\
(\mathrm{n}=17)\end{array}$ & $\begin{array}{l}\text { GP9.5 }+ \\
\text { MPL21 } \\
(\mathrm{n}=16)\end{array}$ & $\begin{array}{l}\text { GP9.5 }+ \\
(\mathrm{n}=16)\end{array}$ & $\begin{array}{l}\text { GP19+ } \\
(\mathrm{n}=16)\end{array}$ & $\begin{array}{l}\text { Placebo } \\
(\mathrm{n}=16)\end{array}$ \\
\hline Pruritus, \% & 53 & 56 & 50 & 69 & 44 \\
Swelling, \% & 6 & - & - & 31 & 6 \\
Burning sensation, \% & 6 & 25 & 6 & 6 & 6 \\
\hline
\end{tabular}

IgG data, which reflected both the small number of subjects per treatment group and natural between-subject variation in immunoglobulin levels.

Specific IgG4 levels were also monitored (fig. 2b), but at only 2 time points (prior to dosing and week 10). All adjuvanted groups showed a greater rise in median values compared to the nonadjuvanted active group (non-statistically significant trends).

IgE Levels

IgE levels increased in all 4 treatment groups over the assessment period but remained unchanged in the placebo group (fig. 3). From week 4 onwards, the rise in median IgE was less pronounced in groups GP9.5 + MPL52 and GP19 + MPL52, in which patients received the highest dose of MPL (non-statistically significant trends).

The degree of heterogeneity in IgE levels was less than that for the IgG data; however, similar caveats relating to treatment group size and intersubject variation are applicable. 

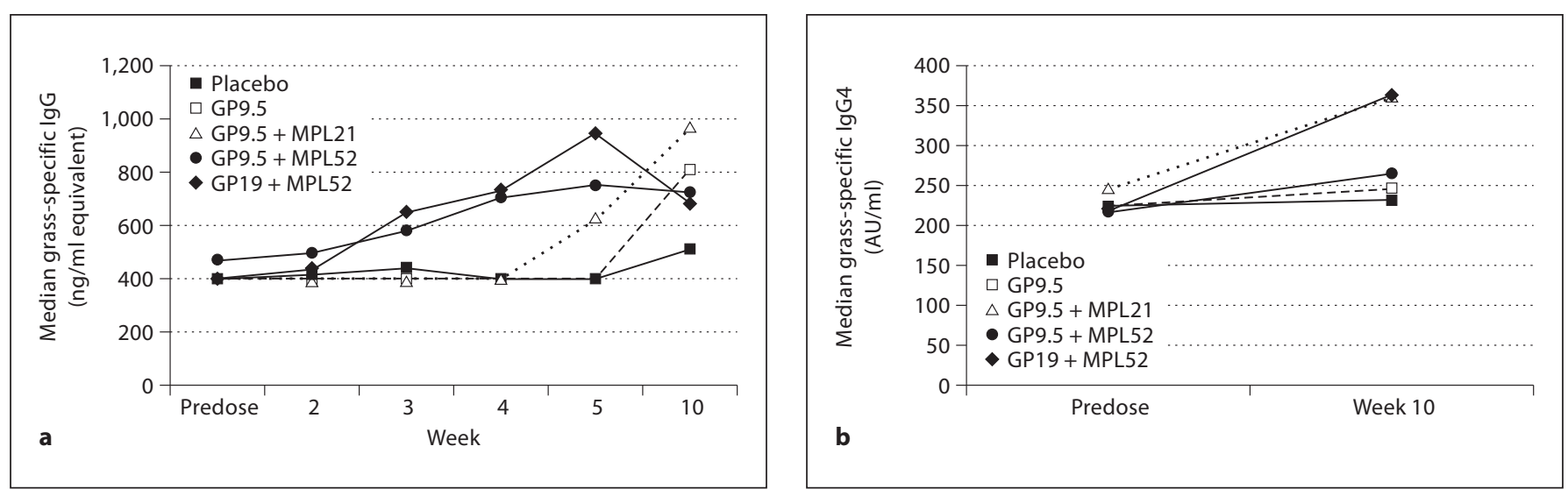

Fig. 2. a Change in median specific IgG levels. b Change in median specific IgG4 levels.

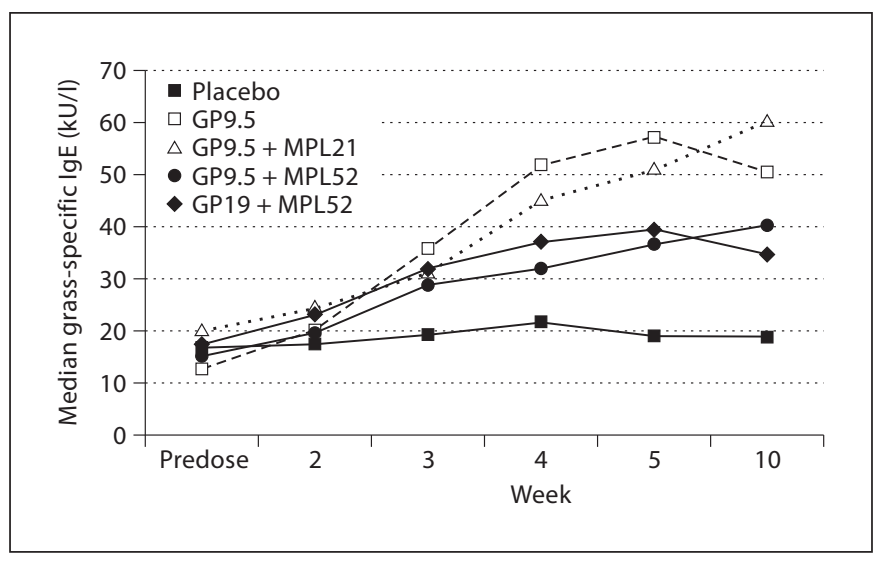

Fig. 3. Change in median specific IgE levels.

\section{Discussion}

To our knowledge, this is the first clinical study to demonstrate both safety and tolerability as well as efficacy of an immunological adjuvant in a SLIT formulation. Following an 8-week preseasonal course of grass pollen SLIT adjuvanted with MPL, the data indicated a measurable clinical effect; 10 weeks after the start of treatment, the number of negative NCTs was double that with placebo for the groups receiving formulations containing the higher doses of MPL.

Several candidate SLIT adjuvants have been evaluated for potential clinical use in animal models. In one study, 30 IL-10-inducing adjuvants were screened first using human monocyte-derived dendritic cells and identifying changes in cytokine production and surface phenotype.
Two lead adjuvants (vitamin D3/dexamethasone and Lactobacillus plantarum) were selected for further appraisal by incorporation into a SLIT formulation which was evaluated in a murine model of established asthma. Both showed enhanced efficacy by reducing airway hyperresponsiveness (AHR) [34].

In another study, two triacylated pseudo-dipeptidic analogues of lipid A were examined. The testing was essentially similar to that used in the previous study, with a final appraisal by monitoring the effect of adjuvanted SLIT on AHR and lung histology in a murine model. The structural relationship of both analogues suggests that they would be Toll-like receptor 4 ligands and as such exert a Th1-like adjuvant effect. Cell studies showed this was indeed so for each analogue, and one additionally induced IL-10 gene expression. This adjuvant was able to reduce AHR, whereas the other did not; thus, a mixed Th1/Treg profile was indicated as a preferred adjuvant characteristic [35].

Three Toll-like receptor 2 ligands were also tested using similar methodology, and one (synthetic lipopeptide Pam3CSK4) was selected as an ideal adjuvant candidate, again demonstrating a Th1/Treg profile [36].

One concern with all 3 of the above-mentioned studies is that the authors reported no detectable changes in specific IgE or IgG resulting from adjuvanted SLIT in the murine model; these antibodies are invariably modulated in concert with successful immunotherapy. In contrast, an adjuvanticity study of MPL showed good antibody responses following 3 or 4 sublingual applications to the mouse. Sera analysis showed that MPL-adjuvanted formulations boosted specific IgG2a, indicating a Th1 bias. Moreover, specific IgA was boosted with nasal and pul- 
monary washes, showing a further boost in secretory IgA [37]. Induction of IgA is not a Th1 characteristic, but is thought to be influenced by TGF- $\beta$ secreted by type 1 Treg cells [38].

To date, clinical data on the extent of induction of specific antibody responses and immunological effects with SLIT have been conflicting $[18,39,40]$.

Compared with the present study, greater specific IgG (and IgE) induction has been observed [7, 8], although it should be noted that in those studies immunological effects were measured before and during/after the pollen season. Thus, the immune system was susceptible to further modulation by natural pollen exposure. In the present study, we observed a rapid trend towards an out-ofseason induction of grass pollen-specific IgG (fig. 2). Subjects who received the allergen-only preparation (group GP9.5) experienced an increase in specific IgG at week 10, but those in groups GP9.5 + MPL21 (21 $\mu \mathrm{g}$ of MPL/dose) and GP9.5 + MPL52 (52.5 $\mu \mathrm{g}$ of MPL/dose) experienced such an increase after 5 and 3 weeks, respectively. This rise was not related to the allergen content of the SLIT formulation, with subjects in group GP19 + MPL52 (52.5 $\mu \mathrm{g}$ of MPL/dose, with double the allergen content of the group GP9.5 + MPL52) also showing IgG induction after 3 weeks.

However, the early rise in specific IgG found with the MPL-adjuvanted groups did not correlate with the best early treatment response, as the highest level of negative NCTs at week 4 was observed in the allergen-only group. One may suggest that the immunotherapy is just beginning the process of arresting an inherent Th2-like bias and that the adjuvant is influencing a changeable immune response to SLIT [24]. One MPL study suggests a possible temporary mechanism; using human PBMCs, the Th2 cytokine IL-5 was shown to be stimulated by MPL alone, whereas in combination with allergen there was a downregulation [29]. A speculative explanation for raised IgG in the MPL groups could be an IgG subclass boost stemming from a temporary stimulation of IL-5, the latter obviously discouraging a good clinical response. It is additionally worth mentioning that MPL should not be regarded as a purely Th1 adjuvant; IL-10 can be induced $[29,41]$ as can seric and secretory IgA [37] and IL-5 [29].

The clinical improvement noted at week 4 was not sustained at week 10 in the nonadjuvanted group. This may be partly due to increased specific IgE, which is a commonly observed effect reported in ongoing allergy immunotherapy. There are probably also changes in cytokine profiles, which of course were not measured.
The overall results indicate that the inclusion of MPL in SLIT may induce an earlier immunological response than is observed with nonadjuvanted SLIT. MPL may potentiate the interaction between allergens and oral dendritic cells (oral Langerhans cells) [30].

The changes in IgE levels suggest a similar early immune-modulating effect. Though the proallergenic IgE levels were increased in all 4 actively treated groups, this effect was less profound in the 2 high-dose MPL groups (fig. 3). Similar effects have been observed following MPLadjuvanted SCIT, where no IgE induction was observed during treatment, and the usual seasonal rise in IgE was also prevented, compared with placebo $[25,26]$. The present study clearly indicates that these changes result from the inclusion of MPL and are not allergen-related; however, the observations need to be confirmed in a large study.

A combination of allergen and MPL has been shown to be synergistic in enhancing murine antigen-specific IgG antibody responses without enhancing antigen-specific IgE responses. Adjuvanted SIT promoted strong IgG2 antigen-specific responses indicative of a Th1-directed response [42]. In vitro studies in oral Langerhans cells demonstrated that MPL upregulated the expression of coinhibitory surface molecules such as B7-1 and B7$\mathrm{H} 3$, which are characteristic of tolerogenic regulatory dendritic cells. In contrast, the surface expression of the costimulatory molecule CD86 and the capacity of oral Langerhans cells to stimulate $\mathrm{T}$ cells was downregulated by MPL, together with induction of the anti-inflammatory cytokine IL-10 and a preferential increase in IFN- $\gamma$ and IL-2 production [30]. It is hoped that future studies with MPL-adjuvanted SLIT will be performed to evaluate effects on Th1, Th2 and Treg responses.

While SLIT is a more convenient form of immunotherapy than conventional SCIT, several studies have failed to show convincing evidence of efficacy in terms of a significant improvement in medication and symptom scores versus placebo during the first year of treatment [43]. The early clinical effect observed in the current study is therefore of considerable importance in the field of SLIT and indicates that immunological adjuvants such as MPL may have an important role in optimizing this form of therapy.

Determination of the safety and tolerability of different dose combinations of sublingually applied MPL and grass pollen allergen was the primary objective of this study. All MPL-grass pollen extract SLIT formulations were well tolerated, with no serious AEs reported. Local reactions, such as pruritus, burning sensations and swelling of the oral cavity, were common in all study groups but were 
usually only of mild severity. The daily total numbers of mild and moderate local AEs diminished with increasing doses of MPL; it is possible that there are beneficial local immunological effects of MPL. In a 3-year study of asthmatics annually treated with an MPL-adjuvanted SCIT vaccine, the patients had an accumulation of MPL, which was observed to be associated with a progressive reduction in local AEs (local reactions per injection: year 1 , 9.8\%; year 2, 5.5\%; year 3,3.9\%) [44]. Of course, it could be argued that the reduction was entirely due to successful immunotherapy, but MPL was still a vaccine constituent.

In the present study, increasing the dose of MPL or allergen did not appear to affect the prevalence of such AEs. Likewise, there was no significant difference in the incidence of systemic reactions between patients who received placebo and those who received active therapy. Even for patients in group GP19 + MPL52, who received the highest dose of allergen and MPL, a mild systemic reaction (pruritus) was only seen in 1 patient. Moderate systemic, severe systemic or anaphylactic shock reactions did not occur during the study, which is in accordance with the current literature on SLIT [6].

The daily sublingual dose of MPL given to groups GP9.5 + MPL52 and GP19 + MPL52 (52.5 $\mu \mathrm{g})$ is similar to the dose of MPL contained in each injection of the MPL-adjuvanted ultra-short course SCIT formulation Pollinex Quattro $(50 \mu \mathrm{g})$. However, the total dose of MPL per treatment course in the SLIT formulation $(2,940 \mu \mathrm{g})$ is approximately 15 times that in a treatment course of Pollinex Quattro $(200 \mu \mathrm{g}$; a treatment course consists of 4 injections), illustrating that it is possible to increase the cumulative dose of MPL (applied orally) without adversely affecting safety.

Although these initial short-term studies of MPL-adjuvanted SLIT in adults over 18 years suggest no major safety concerns, studies in children and adolescents still need to be performed to address safety for these groups. However, it is encouraging that a study of MPL-adjuvanted SCIT in 422 children and adolescents aged 6-18 years who were followed for 3 years has revealed no unexpected safety concerns [45].

Our data demonstrate for the first time an excellent safety profile for MPL-adjuvanted SLIT, with possible clinical and immunologic effects apparent after a preseasonal course of only 8 weeks. Since this was a phase I study, the subject numbers were low, and so there are inevitably limitations, and the statistical data are not highly robust. Analysis of immunological responses was limited to seric antibodies. However, as a proof-of-concept study, the results are certainly promising and encourage a larger, randomized controlled trial with a more comprehensive range of clinical and immunological measurements.

MPL is employed as an adjuvant for injectable antiinfective vaccines such as Fendrix ${ }^{\circledR}$ (hepatitis B) and Cervarix $^{\circledR}$ (papillomavirus, for cancer prevention). It is possible that MPL could also be exploited as an adjuvant for sublingual anti-infective immunotherapy.

\section{Acknowledgments}

This study was funded by Allergy Therapeutics (UK) Ltd., Worthing, West Sussex, UK.

O. Pfaar and L. Klimek have received research grants from ALK-Abello, Denmark; Allergopharma, Germany; Stallergenes, France; HAL, The Netherlands; Artu Biologicals, The Netherlands; Bencard, UK; Hartington, Spain; Lofarma, Italy; Novartis/ Leti, Germany/Spain, and Roxall, Germany. These two authors have also served as advisors and on the speakers' bureaus for the above-mentioned pharmaceutical companies.

\section{References}

1 Bousquet J, Lockey RF, Malling HJ: WHO Position Paper: Allergen immunotherapy: therapeutic vaccines for allergic diseases. Allergy 1998; $53: 1-48$.

- Jacobsen L, Niggemann B, Dreborg S, Ferdousi HA, Halken S, Host A, Koivikko AS, Norberg LA, Valovirta E, Wahn U, Moller C: Specific immunotherapy has long-term preventive effect of seasonal and perennial asthma: 10-year follow-up on the PAT study. Allergy 2007;62:943-948.

3 Passalacqua G, Canonica GW: Long-lasting clinical efficacy of allergen specific immunotherapy. Allergy 2002;57:275-276.
4 Reha CM, Ebru A: Specific immunotherapy is effective in the prevention of new sensitivities. Allergol Immunopathol (Madr) 2007;35:44-51.

5 Amin HS, Liss GM, Bernstein DI: Evaluation of near-fatal reactions to allergen immunotherapy injections. J Allergy Clin Immunol 2006;117:169-175.

-6 Dahl R, Kapp A, Colombo G, de Monchy JGR, Rak S, Emminger W, Fernandez Rivas M, Ribel M, Durham SR: Efficacy and safety of sublingual immunotherapy with grass allergen tablets for seasonal allergic rhinoconjunctivitis. J Allergy Clin Immunol 2006; 118:434-440.
7 Didier A, Malling HJ, Worm M, Horak F, Jager S, Montagut A, Andre C, de Beaumont $\mathrm{O}$, Melac M: Optimal dose, efficacy, and safety of once-daily sublingual immunotherapy with a 5 -grass pollen tablet for seasonal allergic rhinitis. J Allergy Clin Immunol 2007;120:1338-1345.

8 Durham SR, Yang WH, Pedersen MR, Johansen N, Rak S: Sublingual immunotherapy with once-daily grass allergen tablets: a randomized controlled trial in seasonal allergic rhinoconjunctivitis. J Allergy Clin Immunol 2006;117:802-809. 
-9 Wahn U, Tabar A, Kuna P, Halken S, Montagut A, de Beaumont O, Le Gall M: Efficacy and safety of 5-grass pollen sublingual immunotherapy tablets in pediatric allergic conjunctivitis. J Allergy Clin Immunol 2009; 123:160-166.

10 Romagnani S: Immunologic influences on allergy and the Th1/Th2 balance. J Allergy Clin Immunol 2004;113:395-400.

11 Malling H, Weeke B: Position paper: immunotherapy. (EAACI) The European Academy of Allergology and Clinical Immunology. Allergy 1993;48(14 suppl):7-35.

12 Schmidt-Weber CB, Blaser K: Immunological mechanisms in specific immunotherapy. Springer Semin Immunopathol 2004;25: 377-390.

-13 Till SJ, Francis JN, Nouri-Aria K, Durham SR: Mechanisms of immunotherapy. J Allergy Clin Immunol 2004;13:1025-1034.

14 Thunberg S: Immune regulation by CD4+ CD25+ T cells and interleukin-10 in birch pollen-allergic patients and non-allergic controls. Clin Exp Allergy 2007;37:11271136.

15 Schmidt-Weber CB, Blaser K: New insights into the mechanisms of allergen-specific immunotherapy. Curr Opin Allergy Clin Immunol 2005;5:525-530.

16 Till SJ, Durham SR: Immunologic responses to subcutaneous allergen immunotherapy. Clin Allergy Immunol 2008;21:59-70.

17 Akdis CA, Akdis M: Mechanisms and treatment of allergic disease in the big picture of regulatory T cells. J Allergy Clin Immunol 2009;123:735-746.

-18 Cosmi L, Santarlasci V, Angeli R, Liotta F, Maggi L, Frosali F, Rossi O, Falagiani P, Riva G, Romagnani S, Annunziato F, Maggi E: Sublingual immunotherapy with Dermatophagoides monomeric allergoid down-regulates allergen-specific immunoglobulin $\mathrm{E}$ and increases both interferon-gamma- and interleukin-10 production. Clin Exp Allergy 2006;36:261-272.

19 Frati F, Moingeon P, Marcucci F, Puccinelli P, Sensi L, Di CG, Incorvaia C: Mucosal immunization application to allergic disease: sublingual immunotherapy. Allergy Asthma Proc 2007;28:35-39.

-20 Di Gioacchino M, Perrone A, Petracarca C, Di CF, Mistrello G, Falagiani P, Dadorante V, Verna N, Braga M, Ballone E, Cavallucci E: Early cytokine modulation after the rapid induction phase of sublingual immunotherapy with mite monomeric allergoids. Int J Immunopathol Pharmacol 2008;21:969-976.

-21 Ciprandi G, Fenoglio D, Cirillo I, Vizzaccaro A, Ferrera A, Tosca MA, Puppo F: Induction of interleukin 10 by sublingual immunotherapy for house dust mites: a preliminary report. Ann Allergy Asthma Immunol 2005; 95:38-44.

22 O'Hehir RE, Gardner LM, de Leon MP, Hales BJ, Biondo M, Douglass JA, Rolland JM, Sandrini A: House dust mite sublingual immunotherapy. The role for transforming growth factor- $\beta$ and functional regulatory $\mathrm{T}$ cells. Am J Respir Crit Care Med 2009;180: 936-947.

23 Savolainen J, Jacobsen L, Valovirta E: Sublingual immunotherapy in children modulates allergen-induced in vitro expression of cytokine mRNA in PBMC. Allergy 2006;61: 1184-1190.

24 Bohle B, Kinaciyan T, Gerstmayer M, Radakovics A, Jahn-Schmid B, Ebner C: Sublingual immunotherapy induces IL-10-producing $\mathrm{T}$ regulatory cells, allergen-specific T-cell tolerance, and immune deviation. J Allergy Clin Immunol 2007;120:707-713.

25 Drachenberg KJ, Wheeler AW, Stuebner P, Horak F: A well-tolerated grass pollen-specific allergy vaccine containing a novel adjuvant, monophosphoryl lipid A, reduces allergic symptoms after only four preseasonal injections. Allergy 2001;56:498-505.

26 Mothes N, Heinzkill M, Drachenberg KJ, Sperr WR, Kraut MT, Majlesi Y, Semper H, Valent P, Neiderberger V, Kraft D, Valenta R: Allergen-specific immunotherapy with a monophosphoryl lipid A-adjuvanted vaccine: reduced seasonally boosted immunoglobulin E production and inhibition of basophil histamine release by therapy-induced blocking antibodies. Clin Exp Allergy 2003; 33:1198-1208.

27 Patel P, Salapatek AMF: Pollinex Quattro: a novel and well-tolerated ultra-short-course allergy vaccine. Expert Rev Vaccines 2006;5: 617-629.

28 Baldridge J, McGowan P, Evans J, Cluff C, Mossman S, John son D, Persing D: Taking a Toll on human disease: Toll-like receptor 4 agonists as vaccine adjuvants and monotherapeutic agents. Expert Opin Biol Ther 2004; 7:1129-1138.

29 Puggioni F, Durham SR, Francis JN: Monophosphoryl lipid A (MPL) promotes allergen-induced immune deviation in favour of Th1 responses. Allergy 2005;60:678-684.

-30 Allam JP, Peng WM, Appel T, Wenghoefer M, Neiderhagen B, Beiber T, Berge S, Novak $\mathrm{N}$ : Toll-like receptor 4 ligation enforces tolerogenic properties of oral mucosal Langerhans cells. J Allergy Clin Immunol 2008; 121:368-374.

-31 de Graaf-in't VC, Garrelds IM, van Toorenenbergen AW, Gerth van WR: Nasal responsiveness to allergen and histamine in patients with perennial rhinitis with and without a late phase response. Thorax 1997; 52:143-148.

32 Boot JD, Chandoesing P, de Kam ML, Mascelli MA, Das AM, Gerth van Wijk R, de Groot H, Verhoosel R, Hiemstra PS, Diamant Z: Applicability and reproducibility of biomarkers for the evaluation of anti-inflammatory therapy in allergic rhinitis. J Investig Allergol Clin Immunol 2008;8:433442 .

33 Riechelmann H, Bachert C, Goldschmidt O, Hauswald B, Klimek L, Schlenter WW, Tasman AJ, Wagenmann M: Application of the nasal provocation test on diseases of the upper airways. Position paper of the German
Society for Allergology and Clinical Immunology (ENT Section) in cooperation with the Working Team for Clinical Immunology (in German). Laryngorhinootologie 2003; 82:183-188.

34 Van Overtvelt L, Lombardi V, Razafindratsita A, Saint-Lu N, Horoit S, Moussu H, Mascarell L, Moingeon P: IL-10-Inducing adjuvants enhance sublingual immunotherapy efficacy in a murine asthma model. Int Arch Allergy Immunol 2008;145:152-162.

35 Mascarell L, Van Overtvelt L, Lombardi V, Razafindratsita A, Moussu H, Horiot S, Chabre H, Limal D, Moutel S, Bauer J, Chiavaroli C, Moingeon P: A synthetic triacylated pseudo-dipeptide molecule promotes Th1/ TReg immune responses and enhances tolerance induction via the sublingual route. Vaccine 2007;26:108-118.

- 36 Lombardi V, Van Overtvelt L, Horoit S, Moussu H, Chabre H, Louise A, Balazuc AM, Mascarell L, Moingeon P: Toll-like receptor 2 agonist Pam3CSK 4 enhances the induction of antigen-specific tolerance via the sublingual route. Clin Exp Allergy 2008;38:18191829.

37 Wheeler AW, Elliott GT, Cybulski VA, Woroniecki SR: Sublingual immunotherapy adjuvanted with monophosphoryl lipid A. Allergy 2003;58(suppl 74):234.

38 Taylor A, Verhagen J, Blaser K, Akdis M, Akdis CA: Mechanisms of immune suppression by interleukin-10 and transforming growth factor- $\beta$ : the role of regulatory cells. Immunology 2006;117:433-442.

39 Cox LS, Linnemann DL, Nolte H, Weldon D, Finegold I, Nelson HS: Sublingual immunotherapy: a comprehensive review. J Allergy Clin Immunol 2006;117:1021-1035.

40 Pfaar O, Klimek L: Efficacy and safety of specific immunotherapy with a high-dose sublingual grass pollen preparation: a doubleblind, placebo-controlled trial. Ann Allergy Asthma Immunol 2008;100:256-263.

41 Martin M, Michalek SM, Katz J: Role of innate immune factors in the adjuvant activity of monophosphoryl lipid A. Infect Immun 2003;71:2498-2507.

42 Wheeler AW, Marshall JS, Ulrich JT: A Th1inducing adjuvant, MPL, enhances antibody profiles in experimental animals suggesting it has the potential to improve the efficacy of allergy vaccines. Int Arch Allergy Immunol 2001;126:135-139.

43 Wilson D, Torres M, Durham SR: Sublingual immunotherapy for allergic rhinitis. Cochrane Database Syst Rev 2003;CD002893.

44 Urban E, Fischer von Weikersthal-Drachenberg KJ, Zielen S: Allergy vaccination in asthmatic subjects in a real-life setting (poster 674). Allergy 2007;62(suppl 83):244.

45 Rosewich M, Schulze J, Fischer von Weikersthal-Drachenberg KJ, Zielen S: Ultra-short course of immunotherapy in children and adolescents during a 3-yrs post-marketing surveillance study. Pediatr Allergy Immunol 2010;21:e185-e189. DOI: 10.1111/j.13993038.2009.00953.x. 